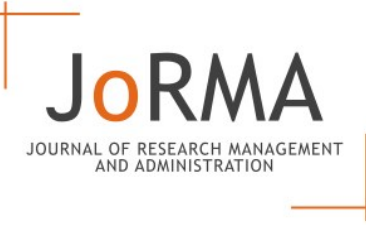

Editorial

\title{
TRANSFORMING RESEARCH MANAGEMENT AND ADMINISTRATION TO KEEP UP WITH THE CHANGING RESEARCH AND INNOVATION LANDSCAPE
}

\author{
Professor Lessing Labuschangne Research, Innovation \& $\quad$ LLabus@unisa.ac.za \\ Commercialisation Department, \\ University of South Africa, \\ Pretoria, South Africa
}

0000-0003-3953-3034

As the world comes to grips with the new reality that COVID-19 has introduced, the societal need for scientific research that is reliable and trustworthy has increased exponentially. What this world pandemic is highlighting is that there is still a definite need for scientific research while forcing us to relook and reconsider its effectiveness. In a relatively short space of time, some researchers were able to acquire major research grants for their research, obtain ethical clearance, establish collaborative agreements and partnerships and disseminate results widely. Before the pandemic some of these processes could take months. What it is demonstrating is that research and innovation systems can change if there is enough reason for them to do so. What we have witnessed is the quick mobilization of researchers and resources to address the challenge. Bureaucracy has made way for agility; research results became more important than research publications and global collaboration became the norm. While there will probably be some challenges post-COVID-19 such as Intellectual Property (IP) ownership and publishing research results that are already in the public domain, the focus now is on solving a life-threatening problem. In all of this, the Research Management and Administration (RMA) community is forced to be innovative and creative in providing effective and efficient support to researchers.

Throughout history, major challenges and crises often provide the best environment for innovation and creativity. Unfortunately, it also means that proper record keeping is often not done. Once the challenge has passed, it becomes difficult to recollect the details and we tend to go back to the way things used to be. What COVID-19 provides us with is an opportunity to consider innovative alternatives to the current research and innovation (R\&l) system. While R\&I happens in various domains, here we will focus mainly on the university domain. 


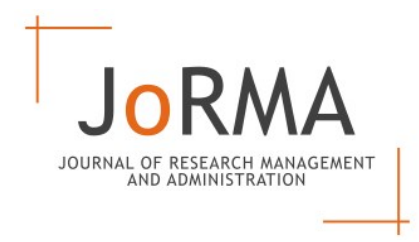

In recent years we have seen an increase in literature questioning the value and impact of research undertaken at universities, especially publicly-funded universities (Georghiou, 2015). In many countries this is fueled by rising tuition fees because of limited resources (Maldonado, 2018). We are also starting to witness the retrenchment of academic staff at some universities due to the pandemic (Hundreds of University Staff to Be Made Redundant Due to Coronavirus / Education / The Guardian, 2020). There is no doubt that the current crisis will put even further strain on the limited resources available for higher education. It is probable that some universities might not survive the pandemic, especially those that are heavily reliant on international students that can no longer travel. During times of crisis, difficult decisions need to be made to ensure survival. One such decision that will face all higher education institutions is its continued investment in research. To make this decision, the leadership of these institutions will need to ask themselves one question. That question is "Why?" or less cryptically, "Why should universities do research?". Answers might range from a moral obligation towards society to intellectual prestige.

In 2019, Elsevier published a report titled "Research Futures - Drivers and scenarios for the next decade" (Mulligan \& Herbert, 2019). In the report, nineteen key drivers are categories into six broad themes. From these themes, three scenarios are proposed for the next ten years. What this report does is to challenge the status quo and theorize about possible futures. Despite the report being published pre-COVID-19, the findings and scenarios remain mostly valid.

The six broad categories are:

1. Funding the future

2. Pathways to open science

3. How researchers work: change ahead

4. Technology: revolution or evolution?

5. Building the future research information system

6. The academy and beyond

The report makes it clear that there are several major issues that will impact the way research is conducted in the future. The RMA community should play an active role in not just supporting the research and innovation systems of the future but also help shape it. The current global pandemic highlights the role that research and higher education institutions can play. Three fundamental questions arise from the current crisis:

Question 1 - What is being researched by universities?

Question 2 - Who is doing the research?

Question 3 - How is research being conducted and disseminated? 


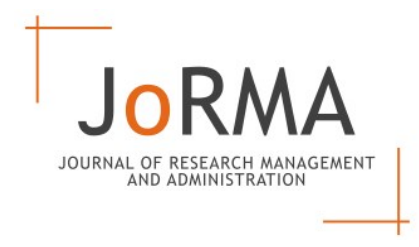

Each question raises several other questions but for the purposes of this article, we only focus on these three and their implications.

Question 1 - What is being researched by universities? It is astonishing to see how many journal articles, scholarly books, conference papers and other research artifacts get produced on an annual basis. Estimates range from 1.8 to 2.5 million scientific papers per annum across a wide spectrum of topics (Jinha, 2010) (Altbach \& De Wit, 2018). While it will be very difficult, if not impossible, to determine the scientific value or impact of each paper, there is no doubt that some of these make little or no contribution to the global body of knowledge. This notion is supported by the continued existence and growth of so many predatory journals, conferences and publishers that publish for the sake of profit (Perlin et al., 2019).

Since the dawn of the modern university in Western society, academic freedom has remained the foundation. Through the years, this freedom has often been challenged at institutional, national and even global level. For the most part, there is still general agreement that academic freedom should be preserved (Reichman, 2015).

For many researchers, the selection of a research focus area is often determined by the funding opportunities available. This then raises the question of who sets the research agenda globally and nationally. For any researcher to have a successful career, research funding is critical.

The question therefore changes from what is being researched to who determines what is being researched. Does academic freedom still exist, or does it come at a huge cost for the researcher?

Question 2 - Who is doing the research? In many instances universities consider themselves to be the main custodians of the traditional research enterprise. In recent years there has been tremendous growth in research being conducted by industry for purposes other than just advancing human knowledge. For 2020, an investment of more than $\$ 2.4$ trillion in R\&D is expected on a global basis, a monetary increase of $2.7 \%$, or $\$ 64$ billion, over what was invested by those same organizations in 2019 (Heney, 2020). The investment for 2018 was $\$ 2.2$ trillion. At the same time, we see a new generation of researchers completing their PhDs and entering the research and innovation industry (Empowering a New Generation of Researchers / ERC: European Research Council, 2018). With this comes new ideas on why research is being conducted, how to create new knowledge and what to do with the results. For this generation, the ultimate achievement is no longer to publish in a prestigious journal but rather to have their research acknowledged, used and rewarded.

This raises the question whether the current research and innovation eco-system will meet the needs and demands of the new generation of researchers. If not, the higher education system might see a migration of researchers towards industry rather than academia. 


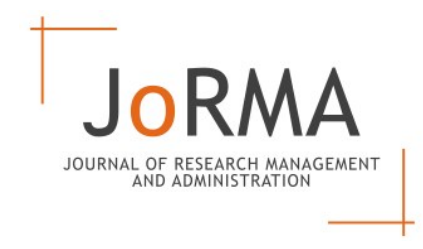

Question 3 - How is research being conducted and disseminated? The growing demand for reliable and trustworthy information has meant that the tradition research lifecycle that takes many years from conceptualizing a study to publishing the results is no longer appropriate. The current pandemic is a case in point. This approach no longer serves the interest of society but rather those that benefit from it. Many are starting to question and even criticize the role commercial scholarly publishers play in the research lifecycle (Larivière et al., 2015) (What Do Commercial Publishers Actually Contribute to Scholarly Publishing? An Interaction with Mrgunn - ArcheoThoughts, 2019). It therefore raises the question why publishing in prestigious journals is still perceived as the main condition for research excellence as opposed to the impact of the said research.

By looking at history, one can see patterns and thereby be better prepared for the future. An example that would be applicable here is when society moved from using horses as transport to using automobiles. The focus was not on the horses and how to keep them occupied but on the needs of society for better transport. As the industry changed, so did the need for support services. For many blacksmiths specializing in the manufacturing and fitment of horse shoes, the end was inevitable. Those that were able to see the changes coming were able to adapt and continued proving different kinds of support services to a new and growing industry. The RMA community therefore should be aware of the changing R\&I environment that is driven by the needs of society and what the future might hold. It is up to us whether we remain blacksmiths or evolve into automechanics.

The Journal of Research Management and Administration (JoRMA) provides the ideal platform to debate the issues, share best practices and contemplate improvements to our environment. I would therefore like to invite readers to respond to the issues raised above by submitting your own articles.

\section{References}

Altbach, P. G., \& De Wit, H. (2018). Too Much Academic Research Is Being Published. International Higher Education, 96, 2-3. https://doi.org/10.6017/ihe.2019.96.10767

Empowering a New Generation of Researchers | ERC: European Research Council. (2018). Retrieved July 27, 2020, from https://erc.europa.eu/news/empowering-new-generation-researchers

Georghiou, L. (2015). Value of Research Policy Paper by the Research, Innovation, and Science Policy Experts (RISE). European Commission, 1-19. https://doi.org/10.2777/732192

Heney, P. (2020). Global R\&D investments unabated in spending growth. R\&D World. https://www.rdworldonline.com/global-rd-investments-unabated-in-spending-growth/

Hundreds of university staff to be made redundant due to coronavirus | Education | The Guardian. (2020). Retrieved July 27, 2020, from https://www.theguardian.com/education/2020/apr/02/hundreds-ofuniversity-staff-made-redundant-due-to-coronavirus 


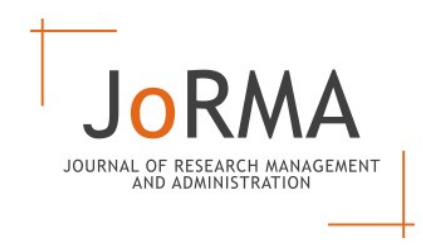

Jinha, A. (2010). Article 50 million: An estimate of the number of scholarly articles in existence. Learned Publishing, 23(3), 258-263. https://doi.org/10.1087/20100308

Larivière, V., Haustein, S., \& Mongeon, P. (2015). Big Publishers, Bigger Profits: How the Scholarly Community Lost the Control of its Journals. MediaTropes, 5(2), 102-110. www.mediatropes.com

Maldonado, C. (2018). Price Of College Increasing Almost 8 Times Faster Than Wages. In Forbes. https://www.forbes.com/sites/camilomaldonado/2018/07/24/price-of-college-increasing-almost-8times-faster-than-wages/\#738afbc766c1

Mulligan, A., \& Herbert, R. (2019). What will the world of research look like 10 years from now? https://www.elsevier.com/connect/elsevier-research-futures-report

Perlin, M. S., Imasato, T., \& Borenstein, D. (2019). The alarming rise of predatory journals. University World News, 1-3. https://www.universityworldnews.com/post.php?story=20180918144241202

Reichman, H. (2015). Does Academic Freedom Have a Future? In Academe (Vol. 101, Issue 6, pp. 8-12). https://www.aaup.org/article/does-academic-freedom-have-future\#.Xx7QWJ4zaUk

What do commercial publishers actually contribute to scholarly publishing? An interaction with mrgunn ArcheoThoughts. (2019). Retrieved July 27, 2020, from https://archeothoughts.wordpress.com/2019/04/29/what-do-commercial-publishers-actuallycontribute-to-scholarly-publishing-an-interaction-with-mrgunn/

\section{Biography}

Lessing is the Executive Director for Research, Innovation and Commercialisation at the University of South Africa (UNISA) and has been working in Research Management and Administration for the last ten years. He was responsible for overseeing Unisa Press, the inhouse scholarly publishing unit at UNISA, from 2011 to 2019. Unisa Press publishes over 50 peer-reviewed journals across a wide array of subject fields.

His career in Higher Education started in 1998 and he established himself as a researcher in his own right. He has published 14 peer-reviewed journal articles, 42 conference papers and 2 book chapters to date. He also supervised 4 Doctoral and 9 Research Masters students to completion. Lessing is an honorary international academic advisor for the PM World Journal (PMWJ) and is also regularly invited to review papers for journals including Computers \& Security (Elsevier) and Information \& Software Technology (Elsevier). He also serves on the editorial board of the Journal of Research Management and Administration (JoRMA).

Contribution Information

Accepting Editor: Kieran Fenby-Hulse.

Cite as: Labuschange L. 2021. Transforming Research Management and Administration to keep up 
with the changing research and innovation landscape. Journal of Research Management and Administration. 1:1, 1-5.

(CC BY-NC 4.0) This article is licensed to you under a Creative Commons Attribution-

NonCommercial 4.0 International License. When you copy and redistribute this paper in full or in part, you need to provide proper attribution to it to ensure that others can later locate this work (and to ensure that others do not accuse you of plagiarism). You may (and we encourage you to) adapt, remix, transform, and build upon the material for any non-commercial purposes. This license does not permit you to use this material for commercial purposes. 